Ambiente \& Água - An Interdisciplinary Journal of Applied Science
ISSN 1980-993X - doi:10.4136/1980-993X
www.ambi-agua.net
E-mail: ambi.agua@gmail.com

\title{
Avaliação de desempenho ambiental de sistemas para fornecimento de água quente para uso doméstico
}

\author{
doi: 10.4136/ambi-agua.1364
}

Received: 10 Apr. 2014; Accepted: 12 Mar 2015

\author{
Luiz Alexandre Kulay $^{1 *}$; Rafael Selvaggio Viñas $^{2}$; Ivanildo Hespanhol $^{3}$ \\ ${ }^{1}$ Universidade de São Paulo(USP), São Paulo, SP, Brasil \\ Departamento de Engenharia Química (PQI) \\ ${ }^{2}$ Fundação Espaço Eco (BASF), São Bernardo do Campo, SP, Brasil \\ ${ }^{3}$ Universidade de São Paulo(USP), São Paulo, SP, Brasil \\ Departamento de Engenharia Hidráulica e Ambiental (PHA) \\ *Autor correspondente: e-mail: luiz.kulay@usp.br, \\ rafael.selv@gmail.com, ivanhes@usp.br
}

\section{RESUMO}

O perfil de consumo do cidadão brasileiro vem se alterando no sentido de buscar alternativas que reduzam despesas. Um dos focos principais dessa mudança de atitude são os dispêndios de eletricidade, em particular no que se refere a sistemas de aquecimento de água. Os fabricantes desses equipamentos agregam valor a seus produtos muito além do preço; uma via regularmente usada por tal estratégia é a valorização do desempenho ambiental. $\mathrm{O}$ presente estudo comparou em termos de desempenho ambiental, quatro modais de aquecimento de água para banho: elétrico, a gás, solar e híbrido, operados sob mesmas condições. A verificação foi realizada por meio da técnica de Avaliação de Ciclo de Vida, para categorias de impacto de mudanças climáticas, acidificação, eutrofização e depleções de recursos hídricos, fósseis e de metais. Os resultados indicaram que os sistemas elétrico e híbrido são menos agressivos ao ambiente em todos os impactos verificados, e que o sistema a gás detém o pior desempenho do conjunto. Por depender de eletricidade nas condições em que o estudo se desenvolveu, o aquecimento solar foi bastante penalizado.

Palavras-chave: consumo energético, aquecimento de água, ACV, impactos ambientais.

\section{Environmental performance evaluation of hot water supplying systems for domestic use}

\begin{abstract}
The consumption profile of Brazilian citizens is changing as alternatives are sought to reduce costs. A major focus of this change of attitude involves expenditures for electricity, particularly in relation to water heating systems. The manufacturers of these devices add value to their products beyond price. A usual strategy is the enhancement of the environmental performance of the product. This study compared four water heating systems: electric, gas, solar and hybrid, using an environmental perspective. The systems were operated under similar conditions. The analysis was conducted by using the Life Cycle Assessment technique, for the impact categories of Climate Change, Acidification,
\end{abstract}


Eutrophication and Water, Metal and Fossil Resource depletion. The results indicated that the electric and hybrid systems are less harmful to the environment for all the impact categories under analysis. On the other hand, the gas system provided the worst performance of the group. The solar heating system was penalized due to its dependence on electricity to operate under the conditions in which the study was conducted.

Keywords: energy consumption, heating water, LCA, environmental impacts.

\section{INTRODUÇÃO}

O perfil de consumo do cidadão brasileiro vem se alterando de maneira significante no curso desta década. Uma pesquisa divulgada pela Confederação Nacional da Indústria (CNI) em 2012 revela que os brasileiros aumentaram suas despesas com saúde, cuidados pessoais e educação, e reduziram custos com viagens e hobbies. Cerca de $40 \%$ da população têm acesso a internet, $27 \%$ contratam plano de saúde privado, e 55\% dos entrevistados preferem fazer compras à vista a parcelar a dívida. A renda média familiar aumentos durante os 12 meses que precederam a pesquisa, entre 2011 e 2012 , e mais $60 \%$ do público amostrado pretende reduzir gastos domésticos por acreditar que a situação econômica do país não é estável (CNI, 2012).

Dentre as despesas ditas como mais incidentes sobre o orçamento familiar, os desembolsos com energia elétrica aparecem com destaque. Um levantamento publicado pela Empresa de Pesquisas Energéticas (EPE) em 2012 revela que o congelador de alimentos é o equipamento que mais consome eletricidade em um domicílio brasileiro, respondendo por 25,1\% dessa classe de despesas (Brasil, 2012b). Dados do Instituto Brasileiro de Geografia e Estatística (IBGE) de 2011 indicam, porém, que apenas 16,4\% das famílias dispõe do utensilio (IBGE, 2012). Os sistemas de aquecimento de água, segundo colocado em custos de eletricidade com $23,7 \%$ das despesas, têm perfil de consumo distinto. O estudo coordenado pela EPE apontou que mais de $70 \%$ das moradias brasileiras com acesso à eletricidade utilizam chuveiro ou ducha com resistência elétrica para este fim. $\mathrm{O}$ sistema consome em média $484 \mathrm{kWh}$ ano ${ }^{-1}$ para cada unidade instalada, gerando uma despesa que pode variar entre $\mathrm{R} \$ 110,79$ e $\mathrm{R} \$ 207,14$ dependendo da localidade. Assim, o consumidor passou a se interessar por opções mais econômicas que o chuveiro, ainda que os custos de aquisição e instalação mostrem-se superiores aos dele (Brasil, 2012b).

Ciente desta demanda os fabricantes de eletrodomésticos disponibilizam no mercado tecnologias alternativas de aquecimento de água, como os sistemas a gás, à energia solar, ou os híbridos, que conjugam duas fontes de calor. Ainda que a variável econômica seja quesito mandatório para aquisição dos sistemas, a concorrência entre as empresas do setor impõe que outros atributos lhes sejam também agregados. Uma prática usual nesse campo consiste em valorizar o desempenho ambiental da tecnologia, associando-a ao uso de energias limpas como a solar, ou a combustíveis que produzam menos poluição atmosférica, como no caso do gás natural. Nem sempre, tais estratégias se fundamentam de maneira adequada.

O presente estudo busca contribuir para o tema, ao avaliar o desempenho ambiental da disponibilização de água quente para banho desde quatro tecnologias de aquecimento: solar; a gás; com resistência elétrica; e híbrida: uma composição entre solar e à resistência. Selecionou-se a cidade de São Paulo como cenário para realização do estudo pelo fato desta ter consumido em 2012 exatos 29,3 TWh de eletricidade, 6,5\% da demanda do país, e dos quais 41,3\% sustentaram o uso residencial (São Paulo, 2012).

Uma análise dessa natureza será efetiva para o propósito a que se destina, apenas caso seja realizada a partir de uma perspectiva sistêmica, em que se avaliem não apenas os efeitos sobre o meio ambiente associados à atividade em si de fornecimento de água quente para banho, mas também, ações à montante e à jusante de sua cadeia produtiva que suportem o 
atendimento da função. Para que tal condição fosse satisfeita decidiu-se fazer uso da técnica de Avaliação de Ciclo de Vida (ACV) na referida avaliação.

\subsection{Breve descrição dos sistemas de aquecimento de água para banho}

A seguir é realizado um breve relato dos princípios de funcionamento de cada um dos sistemas em análise, somando vantagens e desvantagens das mesmas tecnologias.

- Chuveiro elétrico: aparelho instalado em uma das terminações de rede de água, que é dotado de pequenos orifícios para dispersão deste fluído. O chuveiro é composto de dois resistores espiralados de potências diferentes, confeccionados em metais que se aquecem rapidamente, e de um diafragma de borracha. A água circula pelo chuveiro e pressiona o diafragma, que por sua vez aproxima os contatos da resistência aos contatos energizados, situados no cabeçote do aparelho. Ao passar pelos terminais do resistor que estão a elevada temperatura, a água se aquece. A potência nominal dos chuveiros disponíveis no mercado varia entre $4400 \mathrm{~W}$ e $7600 \mathrm{~W}$ com tendência de aumento. A escolha do chuveiro elétrico como meio de aquecimento de água na maior parte dos domicílios brasileiros se deve, em primeira instância ao seu baixo custo inicial que varia de $\mathrm{R} \$ 19,90$ a $\mathrm{R} \$ 499,00$ e as facilidades de instalação e operação (CIRRA, 2010; Brasil, 2012b).

- Aquecimento à energia solar: sistema composto de coletores solares e reservatório. Nos coletores a radiação solar de faixa de comprimento de onda infravermelho entre $4000<\lambda$ $(\mathrm{nm})<50000$, é captada nos horários de insolação. Nessas condições, a energia solar é convertida em energia térmica e transferida para água. $\mathrm{O}$ reservatório que a contém consiste de cilindro metálico isolado do meio externo. A caixa d'agua alimenta o reservatório sempre que necessário para mantê-lo cheio constantemente. Durante longos períodos sem insolação, ou mesmo, quando esta se faz insuficiente, emprega-se um aquecedor auxiliar operado via energia elétrica para adequar a temperatura da água à condição definida pelo usuário para o banho. Esta energia auxiliar é proporcionada por resistência localizada no interior do tanque de armazenamento de água quente. Um sistema de aquecimento solar tem custo inicial da ordem de $\mathrm{R} \$ 4.000,00$. Sua vida útil alcança 15 anos, mas para isso requer-se manutenção constante. A procura por esta modalidade tem crescido em virtude da economia mensal de energia que proporciona, e do fato de fazer uso de energia limpa (CIRRA, 2010).

- Aquecimento a gás: utiliza-se um aquecedor instantâneo a partir do qual a água elava sua temperatura, por condução, à medida que circula no interior de uma serpentina fabricada em cobre. A serpentina está em contato indireto com uma chama viva mantida pela queima de gás natural. Além do aquecedor, o sistema compõe-se de trocador de calor constituído pelo conduto em que ocorre a liberação dos gases da combustão. Nessa tecnologia de aquecimento o controle de calor se dá por meio de termostato. Os sistemas a gás propiciam água quente com pressão satisfatória, e tem menores taxas de desperdício que as unidades de aquecimento solar. Além disso, a tecnologia traz custos mensais inferiores aos do sistema elétrico. $\mathrm{O}$ desembolso inicial a ser efetuado para sua aquisição e instalação é, no entanto, expressivo, podendo variar entre $\mathrm{R} \$ 950,00$ e $\mathrm{R} \$ 2.000,00$ (Brasil, 2012b).

- Sistema híbrido: associa os coletores solares e reservatórios do aquecedor solar com um chuveiro elétrico. As placas coletoras são responsáveis pela absorção da radiação solar; em períodos de pouca insolação a temperatura da água definida para o banho será alcançada com o acionamento da resistência elétrica do chuveiro gerando dessa forma um consumo de energia inferior ao do sistema elétrico. Outra vantagem do sistema híbrido reside no custo inicial, inferior a $\mathrm{R} \$ 900,00$. No entanto, a adoção desse sistema predispõe a existência de um chuveiro elétrico em cada ponto de consumo (CIRRA, 2010; Brasil, 2012b). 


\subsection{Avaliação de Ciclo de Vida: fundamentos teóricos}

Para Sugawara (2012) a Avaliação do Ciclo de Vida (ACV) pode ser entendida como uma técnica quantitativa de determinação dos impactos ambientais associados ao ciclo de vida do atendimento de certa função, por parte de um produto, processo ou serviço. Esse mesmo autor conceitua ciclo de vida como o conjunto de interações antrópicas a ser constituído para que o propósito supramencionado seja alcançado.

$\mathrm{O}$ fato de se constituir em técnica de diagnóstico abre diversas perspectivas em termos de usos e aplicações para a ACV. Dentre estas, devem merecer especial destaque: a comparação de desempenho entre produtos que exerçam a mesma função; emissão de rótulos ou selos; o projeto de novos produtos e processos, ou aperfeiçoamento daqueles já existentes; definição de Políticas Públicas; e suporte a ações de comunicação (Hansen, 2013).

Em termos de método a abordagem proposta na norma ABNT NBR ISO 14040 (ABNT, 2009a) para condução de estudos de ACV é bem aceita pela comunidade científica dedicada ao estudo e desenvolvimento do tema. Um estudo conduzido segundo aquele enfoque compreende por etapas: Definição de Objetivo e Escopo; Análise de Inventário (ICV); Avaliação de Impactos (AICV); e Interpretação.

- A Definição de Objetivo e Escopo trata de estabelecer as bases conceituais do estudo. Assim são ali estabelecidos aspectos orientativos como: os propósitos da ACV em si; os fins para os quais será empregada; e, ao público-alvo a que se destina (Hansen, 2013).

$\mathrm{Na}$ Definição de Escopo trata de fixar elementos estruturais do exercício da técnica. Dentre estes se destacam: a função para a qual o produto, processo, ou serviço terá seu desempenho testado via ACV, a Unidade Funcional, ou seja, a quantidade de função a ser atendida pelo bem em análise; e a delimitação do chamado Sistema de Produto, que consiste da colocação de fronteiras que separem a porção do espaço sobre a qual será aplicada a ACV do ambiente externo, e de outros sistemas antrópicos. A lista de requisitos se completa com: estabelecimento de premissas que pautem a coleta de dados, de forma que o modelo derivado desta ação seja consistente com realidade que pretende espelhar; prescrição de requisitos quanto à origem e representatividade estatística dos dados; formulação de critérios de alocação; e seleção do método mais adequado para avaliação de impactos (Sugawara, 2012).

- A Análise de Inventário (ICV) quantifica correntes de entrada, recursos naturais, ou bens de produção, materiais e energéticas, e saída (rejeitos), também de matéria e energia, que são dispostos no ambiente associadas ao sistema para o qual a ACV está sendo aplicada. Essa quantificação ocorre quanto ao Fluxo de Referência, ou seja, à quantidade de produto, processo, ou serviço necessário ao atendimento da Unidade Funcional (Sugawara, 2012).

- A etapa de Avaliação de Impacto (AICV) trata de magnificar impactos proporcionados pelo sistema ao ambiente e ao ser humano no curso do exercício da função em análise. Para tanto as correntes que montam o inventário são totalizadas em termos das contribuições que imputam às categorias de impacto ambiental selecionadas também na Definição de Escopo.

São exemplos de categorias de impacto: Mudanças Climáticas, Eutrofização, Acidificação, Estresses toxicológicos sobre saúde humana e ecossistemas, e Depleção de recursos (Hansen, 2013).

- A Interpretação é a última das etapas de um estudo de ACV. Por seu intermédio é possível avaliar o rigor com que a técnica foi aplicada via confrontação entre si e com documentos normativos, de elementos estruturais de etapas executivas da ACV (ABNT, 2009b).

\subsection{ACV de sistemas de aquecimento de água}

O levantamento de referências junto à literatura acadêmico-científico que trata do tema em análise revelou que nos últimos anos foram realizadas pesquisas dentro de espectro 
bastante variado, ainda que sempre dentro do tema central, sistemas de aquecimento de água envolvendo ACV. Buyle et al. (2013) efetuaram uma revisão da aplicação da técnica de ACV para a indústria da construção civil. Os autores concluíram que a fase de uso pode responder por até $90 \%$ das cargas ambientais geradas em um edifício convencional dada a existência de sistemas que proporcionem conforto térmico em seu interior. Chow e Ji (2012) examinaram via $\mathrm{ACV}$, o desempenho de diferentes sistemas híbridos solar-elétrico para aquecimento doméstico de água em Hong-Kong. Os resultados mostraram que o modelo do tipo casca-tubo é superior ao homólogo de perfil canal-retangular.

Sumper et al. (2011) usaram ACV em aquecimentos solares com módulos de silício policristalinos (PV) e potência de $200 \mathrm{~kW}$ para avaliar emissão de gases de efeito estufa (GEE). Determinou-se ainda neste caso a taxa de retorno de energia da unidade, que foi comparada depois com as de duas outras tecnologias: de módulos mono-cristalino, e filme fino. A taxa de retorno do sistema PV em análise foi estimada em 4,4 anos e seu desempenho em termos de emissões de GEE mostrou-se melhor que os dos homólogos. Hazami et al. (2013) compararam sistemas domésticos de aquecimento de água para a Tunísia em termos ambientais e econômico. Tais desenvolvimentos mostraram que o aquecimento solar foi superior a seus congêneres a gás e elétrico, tanto em termos ambientais impondo reduções significantes de emissão de gás carbônico, como de custos de operação.

Kattan e Ruble (2012) também confrontaram em termos ambientais e econômicos quatro sistemas de aquecimento de água para a realidade do Líbano. O boiler elétrico mostrou-se mais poluente e custoso do que as outras opções em análise: diesel, gás liquefeito de petróleo, e biomassa. O estudo constata que o subsídio dado ao diesel constitui-se em barreira à implantação de energias renováveis neste setor. Os desempenhos técnico e ambiental de um aquecedor solar de uso doméstico na cidade de Tessalonica, Grécia foram examinados por Koroneos e Nanaki (2012) usando a ACV. Foram observadas contribuições pouco significantes para as categorias de AICV avaliadas: Efeito Estufa, Acidificação, Eutrofização, Formação de foto-oxidantes, e descarte no ambiente de Metais Pesados e de compostos carcinogênicos.

\section{MATERIAL E MÉTODO}

\subsection{Modelagem dos sistemas de aquecimento de água}

A Figura 1 descreve de maneira simplificada do processo de aquecimento de água para banho para cada tecnologia em análise. Destacam-se no esquema ações de potabilização da água, fontes de fornecimento de energia, e transportes relativos a cada sistema. Quando analisada sob um enfoque cartesiano e pragmático a ação de tomar banho quente compreende atividades de: fornecimento de água em condições adequadas a este uso; seu aquecimento; a desinfecção proporcionada pelo banho; e o tratamento dos despejos líquidos dele decorrentes até limites suficientes para que sua absorção pelo corpo coletor lhe cause mínimas alterações.

Os sistemas avaliados aplicam diferentes tecnologias, materiais de construção, componentes, e formas de operação, para providenciar o aquecimento da água. Assim, a definição de uma base comum de comparação entre eles requereu a fixação prévia de parâmetros de desempenho técnico relativos à função em análise. São eles: Fonte de calor usada em cada sistema; Configuração, modelo, e especificidades da tecnologia de aquecimento; Eficiência de aquecimento (condicionada à transferência de calor a partir da fonte); vida útil do sistema; temperaturas da água, inicial, e a ser mantida pelos sistemas de aquecimento; número de banhos (neste caso, tomou-se por critério que o banho ocorreria após longo período de inatividade do sistema com o propósito de eliminar a influência de eventos sucessivos sobre o processo de aquecimento); tempo de duração do banho; consumo de água (que compreendeu as parcelas despendidas no banho em si; e descartada por conta do aquecimento da água desde a temperatura inicial, até aquela em que o banho ocorre). 


\subsection{Avaliação do Ciclo e Vida do fornecimento de água para banho}

Este estudo foi realizado em consonância com o arcabouço conceitual estabelecido nas normas ABNT NBR ISO 14040 e 14044 (ABNT, 2009a; 2009b). Quanto a "Definição de Objetivos" a iniciativa consistiu em comparar o desempenho ambiental de sistemas de fornecimento de água quente para banho. Os resultados desta ação trazem elementos para o aprimoramento ambiental das referidas tecnologias junto a seus fabricantes, e suportam o processo de tomada de decisão realizado pelo consumidor para sua aquisição.

Quanto à "Definição de Escopo", foram estabelecidos os seguintes requisitos:

\section{Definição de Função, Unidade Funcional e Fluxo de Referência do Produto:}

- A função definida para a análise foi: "fornecer água quente em volume suficiente para um banho a ser realizado após longo período de inatividade do sistema de aquecimento".

- Esta necessidade foi expressa em termos de Unidade Funcional (UF) como: "fornecer água a $45^{\circ} \mathrm{C}$ para um banho de tempo médio de duração de 8,1 minutos". A duração do banho de 8,1 minutos e as temperaturas médias inicial e pós calefação da água de $21,5^{\circ} \mathrm{C}$ e $45^{\circ} \mathrm{C}$ decorrem de ensaios efetuados pelo Centro Internacional de Referência em Reúso de Água (CIRRA) para a cidade de São Paulo (CIRRA, 2010).

- A determinação do Fluxo de Referência (FR) predispôs uma avaliação de características estruturais e operativas de cada sistema. Isso ocorreu porque os dispêndios de água e energia para o atendimento da UF variam por modal de aquecimento, sobretudo dada a premissa de longa inatividade entre funcionamentos.

Foram obtidos de fontes técnicas e manuais de operação cedidos por fabricantes de equipamentos (Lorenzetti, 2011a; 2011b), dados de potência, coeficientes de conversão e transferência de energia, e aspectos construtivos e dimensionais de cada arranjo. A estes se adicionaram valores de tempos de reposições sucessivas de peças para cada sistema: elétrico (cinco anos); solar (15 anos); gás (20 anos) e híbrido (15 anos) (CIRRA, 2010; Lorenzetti, 2011a; 2011b). Com este conjunto de parâmetros determinou-se os volumes de água, quantidade de energia, e taxa de utilização do sistema, correspondentes ao FR que seriam necessários em cada caso para atender à UF do estudo. A Tabela 1 traz indicados esses valores.

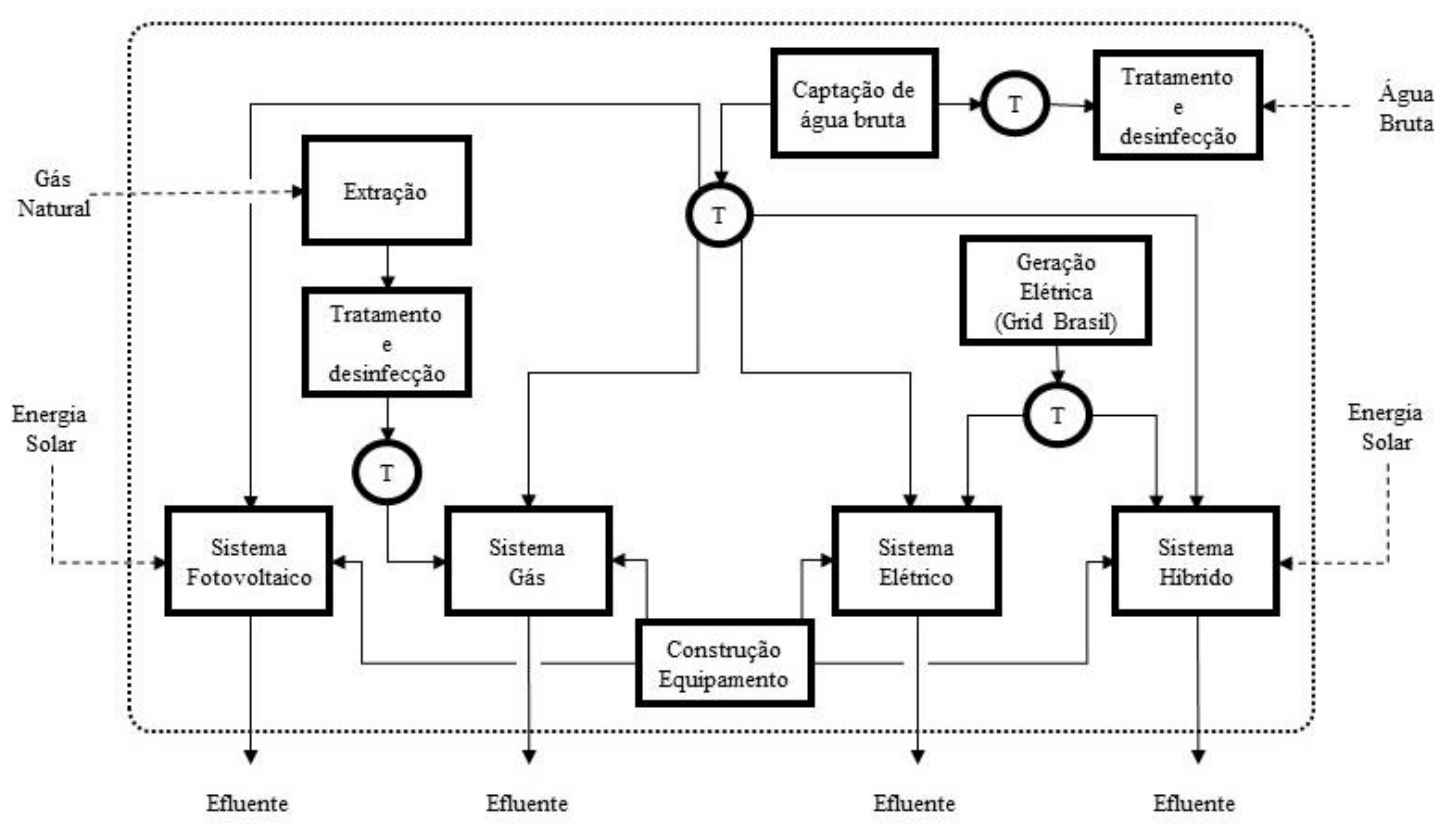

Figura 1. Esquema simplificado dos sistemas de produção de água aquecida para banho. 


\subsection{Sistema de Produto}

O Sistema de Produto definido para o estudo consta na Figura 2. Os sistemas de aquecimento de água são indicados de maneira genérica na mesma ilustração.

Tabela 1. Consumos de água, energia e taxa de utilização dos Sistemas.

\begin{tabular}{lcccc}
\hline \multirow{2}{*}{ Parâmetro de desempenho/banho } & \multicolumn{4}{c}{ Sistema por fonte de energia } \\
\cline { 2 - 5 } & Solar & Gás & Elétrico & Híbrido \\
\hline Consumo de água $(\mathrm{kg})$ & 67,62 & 69,98 & 33,66 & 33,23 \\
Consumo de energia elétrica $(\mathrm{kWh})$ & 0,60 & - & 0,59 & 0,45 \\
Consumo de Gás $\left(\mathrm{m}^{3}\right)$ & - & 6,73 & - & - \\
Taxa de utilização do sistema $(\mathrm{p})$ & 1,83 E-04 & 1,37 E-04 & 5,48 E-04 & 1,83 E-04 \\
\hline
\end{tabular}

Para efeito de desenvolvimento do estudo estes foram definidos como o conjunto composto pelo modal de aquecimento de água: solar, a gás, elétrico e híbrido, e a estrutura do chuveiro, a qual se admitiu comum às alternativas analisadas.

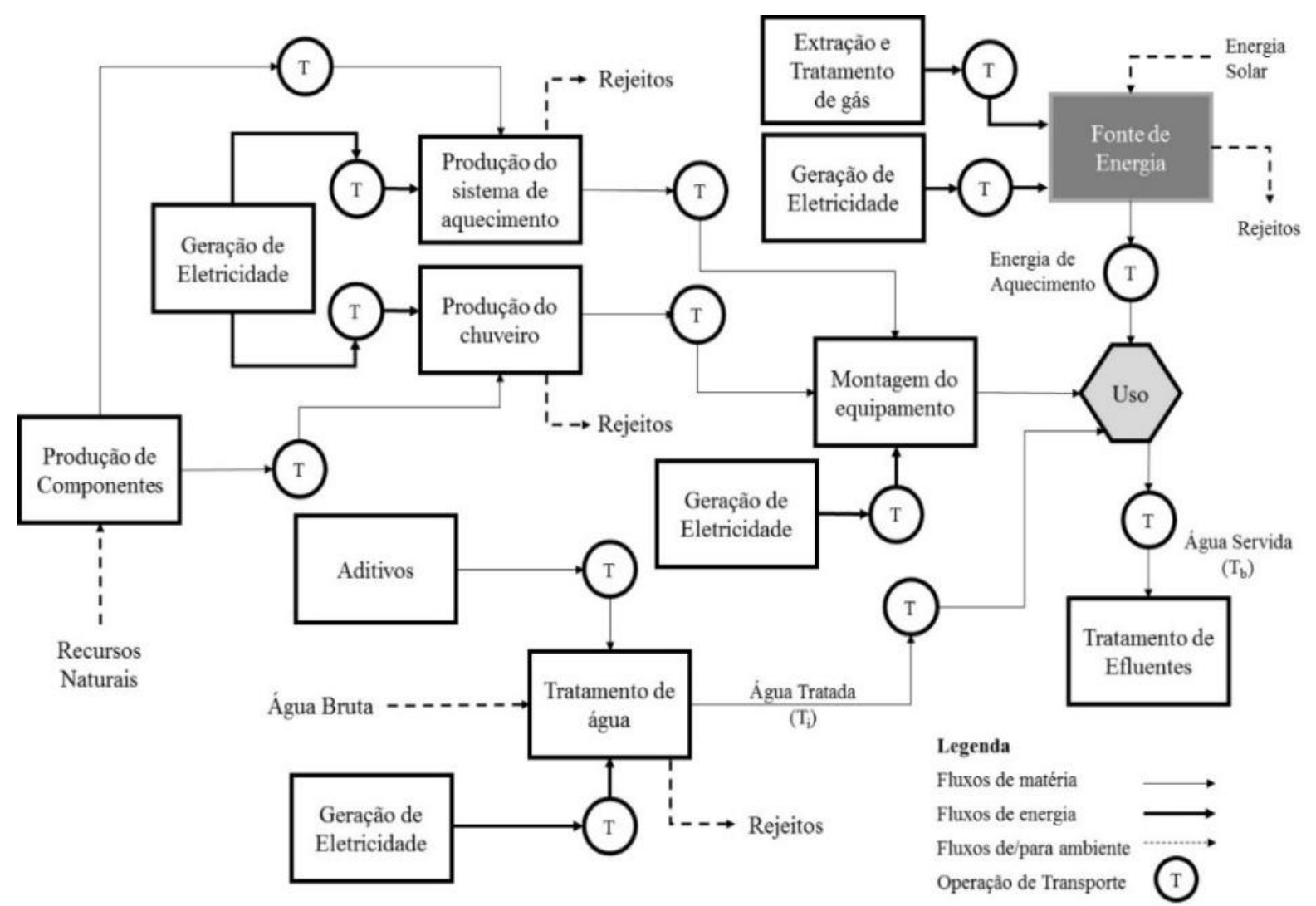

Figura 2. Sistema de Produto Sistemas de processo de fornecimento de água quente para banho.

A modelagem realizada para efeito de elaboração de Sistema de Produto de cada sistema de aquecimento tomou por premissas que estes seriam compostos da somatória dos materiais de construção que configuram cada qual de seus componentes. Cada unidade foi desmontada, seus materiais de construção agrupados por classes, e dentro destas, em subclasses tais como: Materiais Metálicos: aço carbono (aço C), aço inox, alumínio, cobre, latão e ligas metálicas (FeCrAl); Materiais Fibrosos: papel; Materiais Vítreos: vidro; Materiais Poliméricos e Resinosos: ABS (acrilonitrila butadieno estireno), acrílico, PS (poliestireno), PE (polietileno), 
PVC (cloreto de polivinila), PP (polipropileno), e resina epóxi; e, Adesivos: borrachas. Estes foram então pesados para determinação da respectiva contribuição mássica.

As dificuldades de conseguir dados, que representassem de maneira satisfatória consumos e gerações decorrentes da montagem de cada sistema de aquecimento, fizeram com que essas mesmas fossem desconsideradas das modelagens. Essa lacuna proporcionou uma imprecisão cuja magnitude foi aferida por intermédio de análise de sensibilidade que mostraram que as ausências não trouxeram alterações significantes dos resultados do estudo.

Integram o Sistema de Produto recursos naturais: água bruta, gás natural, luz solar, e petróleo; insumos: aditivos para desinfecção e potabilização de água bruta e tratamento de efluentes, e; utilidades: água industrial e de consumo humano, e energia elétrica.

Os recursos antrópicos foram avaliados quanto desempenho ambiental desde suas origens, até as respectivas participações para que a função do estudo fosse cumprida. Ações de transporte por tubulação, e modais veiculares como caminhões e navios, e os combustíveis nelas empregados: gás natural e óleo diesel foram contemplados da mesma forma. Além disso, admitiu-se que os efluentes do banho tratados previamente ao lançamento no corpo coletor e assim, os consumos e descartes originados desta ação foram incluídos.

Critérios de Exclusão: a decisão quanto a excluir correntes de matéria e energia de cada modelo de Sistema de Produto seguiu diretrizes formuladas da norma ABNT NBR ISO 14044 (ABNT, 2009b). A primeira delas fez excluir fluxos de matéria ou energia de contribuição cumulativa fosse inferior a $1 \%$ do total das entradas, ou saídas, da etapa a que se relacionam. A segunda diretriz levou em conta o potencial de impacto das correntes eliminadas pela regra anterior. Quando os aportes mostraram-se relevantes, tais fluxos foram reintegrados ao ICV.

\subsection{Procedimentos de Alocação}

Não houve necessidade de aplicação de procedimentos de alocação em quaisquer dos Sistemas de Produto em estudo.

\subsection{Tipos de Impactos e Método de AICV}

Cosiderando os propósitos a que se destina a análise, bem como, particularidades dos sistemas em análise pela ACV decidiu-se adotar o modelo ReCiPe midpoint $(\mathrm{H})$, versão 1.07 para efeito de AICV (Goedkoop et al., 2009). Neste âmbito foram selecionadas para o estudo categorias de impacto de: Mudanças Climáticas (CC); Acidificação Terrestre (AC); Eutrofização aquática (EUA); e as Depleções de Recursos Hídricos (WD); de Metais (MD); e de Recursos Fósseis (FD).

\subsection{Qualidade dos Dados}

Os requisitos quanto a Qualidade dos dados são descritos a seguir na forma de seus elementos constituintes. Quanto à "Cobertura temporal", os dados primários medidos diretamente junto aos processos e etapas em análise foram coletados ao longo do período 2009-2011. Os dados secundários de levantamento junto à literatura técnica, bancos de dados, ou procedência equivalente foram levantados para o período 2011-2012.

Quanto à "Cobertura geográfica" a produção dos sistemas de aquecimentos considerou como universo a RMSP para o caso das unidades elétrica, solar e híbrida. O mesmo ocorreu com a construção do chuveiro. Como o sistema a gás é manufaturado na cidade de Zhongshan, China, tratou-se de modelar aspectos produtivos a ele associados a partir daquela realidade. Definiu-se a cidade de São Paulo como local aplicação dos sistemas e assim, os tratamento e distribuição de água, fornecimento de eletricidade, e transportes foram também estabelecidos quanto à espacialidade. Por fim, incluíram-se ainda regiões de Gran Chaco e Sud Yungas (Bolívia) nas quais ocorre extração de parte do gás natural presente na matriz 
energética do Brasil. A análise deste recurso natural compreendeu ainda os Municípios de Santos e Campos, localizados no Estado de São Paulo, e do Rio de Janeiro.

A "Cobertura tecnológica" das construções do chuveiro, e dos sistemas de aquecimento remete a equipamentos disponíveis no mercado consumidor. Exceção foi feita ao sistema híbrido, modelado pela composição dos sistemas elétrico e solar, desde valores médios de taxas de utilização.

\subsection{Tipo e Fonte de dados}

Quanto ao "tipo", usaram-se dados primários para quantificação da massa de materiais de construção de cada conjunto sistema de aquecimento-chuveiro, e dos transportes de cada sistema de produto. Já o processamento e a distribuição de água; geração e transporte de energias elétrica e térmica; extração e tratamento de gás natural; e tratamento de efluentes; foram modeladas a partir de dados secundários. Constituíram-se em "fontes de dados" para realização deste estudo:

- Relatório técnico elaborado por CIRRA (CIRRA, 2010) que avalia o consumo de insumos nos sistemas analisados por esta iniciativa;

- Manuais de uso dos equipamentos e sistemas (Lorenzetti, 2011a; 2011b); e

- Balanço Energético Nacional - BEN (Brasil, 2012a) e Energy Balance of non-OECD Countries (IEA, 2011), desde os quais coletaram-se dados da composição das matrizes energéticas do Brasil e da China.

Quando da impossibilidade de obtenção de valores típicos de consumos e gerações para os Sistemas de Produto, fez-se uso de bancos de dados internacionais de apoio a ACV. Nesses casos foram efetuadas exaustivas análises de sensibilidade até que os dados se incorporassem os modelos.

\subsection{Premissas e Hipóteses}

Os modelos de Sistemas de Produto consideraram premissas específicas para efeito de construção dos ICVs. As mais relevantes são descritas a seguir:

- Inclusão de consumos e descartes materiais e energéticos que pudessem ser validados por procedimentos quantitativos como balanços de matéria e energia;

- Desconsideração de embalagens e bens de capital afora os envolvidos na composição dos sistemas de aquecimentos em estudo, e utilização de mão-de-obra;

- Nos transporte realizados por modais veiculares foram contabilizadas somente emissões para a atmosfera decorrentes da queima de óleo diesel;

- No transporte de gás natural via tubulação foram admitidas emissões para o ar decorrentes de vazamentos e da queima do próprio recurso para seu deslocamento;

- Definiu-se que a eletricidade usada na extração e tratamento do gás natural que ocorrem na Bolívia seria produzida via ciclo combinado movido, por este combustível.

A caracterização da qualidade dos despejos líquidos do processo de lavagem foi adotada de maneira indistinta, na modelagem da etapa de tratamentos de efluentes para todos os Sistemas de Produto sob avaliação. A Tabela 2 mostra valores para os consumos de recursos e gerações de rejeito que mais influenciaram os resultados em termos de impactos ambientais para os sistemas analisados. 
Tabela 2. Inventário de Ciclo de Vida dos sistemas de aquecimento em análise.

\begin{tabular}{lccccc}
\hline Correntes & Unidade & Solar & Gás & Elétrico & Híbrido \\
\hline & \multicolumn{2}{c}{ Entradas - Recursos Naturais } & & \\
\hline Óleo Cru, subsolo & $\mathrm{kg}$ & $7,37 \mathrm{E}-03$ & $2,45 \mathrm{E}-02$ & $3,69 \mathrm{E}-03$ & $6,41 \mathrm{E}-03$ \\
Gás Natural, subsolo & $\mathrm{m}^{3}$ & $2,40 \mathrm{E}-04$ & $7,16 \mathrm{E}+00$ & $1,19 \mathrm{E}-04$ & $1,20 \mathrm{E}-04$ \\
Carvão Mineral, subsolo & $\mathrm{kg}$ & $1,36 \mathrm{E}-02$ & $6,16 \mathrm{E}-02$ & $8,89 \mathrm{E}-03$ & $1,11 \mathrm{E}-02$ \\
Minério de Ferro, subsolo & $\mathrm{kg}$ & $3,03 \mathrm{E}-03$ & $7,00 \mathrm{E}-02$ & $1,02 \mathrm{E}-03$ & $2,74 \mathrm{E}-03$ \\
Água, superficial & $\mathrm{m}$ & $1,17 \mathrm{E}-01$ & $1,21 \mathrm{E}-01$ & $5,84 \mathrm{E}-02$ & $5,78 \mathrm{E}-02$ \\
\hline & $\mathrm{Saída}-\mathrm{Emissões} \mathrm{Atmosféricas}$ & & \\
\hline $\mathrm{CO}_{2}$, fóssil & $\mathrm{kg}$ & $8,77 \mathrm{E}-02$ & $1,32 \mathrm{E}+01$ & $6,33 \mathrm{E}-02$ & $7,02 \mathrm{E}-02$ \\
$\mathrm{CO}_{2}$, uso do solo & $\mathrm{kg}$ & $7,75 \mathrm{E}-04$ & $5,04 \mathrm{E}-05$ & $7,43 \mathrm{E}-04$ & $5,83 \mathrm{E}-04$ \\
$\mathrm{CH}_{4}$, fóssil & $\mathrm{kg}$ & $1,35 \mathrm{E}-04$ & $2,64 \mathrm{E}-03$ & $7,25 \mathrm{E}-05$ & $1,16 \mathrm{E}-04$ \\
$\mathrm{CH}_{4}$, uso do solo & $\mathrm{kg}$ & $1,13 \mathrm{E}-04$ & $2,50 \mathrm{E}-05$ & $9,98 \mathrm{E}-05$ & $7,95 \mathrm{E}-05$ \\
$\mathrm{SO}_{2}$ & $\mathrm{~kg}$ & $2,89 \mathrm{E}-04$ & $4,37 \mathrm{E}-04$ & $1,66 \mathrm{E}-04$ & $2,46 \mathrm{E} 04$ \\
$\mathrm{NO}_{\mathrm{x}}$ & $\mathrm{kg}$ & $1,89 \mathrm{E}-04$ & $1,23 \mathrm{E}-03$ & $1,25 \mathrm{E}-04$ & $1,55 \mathrm{E}-04$ \\
\hline & $\mathrm{Saída}-$ Perdas Hídricas & & \\
\hline $\mathrm{Fosfatos}\left(\mathrm{PO}_{4}{ }^{3-}\right.$ ) & $\mathrm{kg}$ & $2,10 \mathrm{E}-04$ & $2,63 \mathrm{E}-04$ & $9,44 \mathrm{E}-05$ & $1,88 \mathrm{E}-04$ \\
$\mathrm{Mn}^{2+}$ & $\mathrm{kg}$ & $9,64 \mathrm{E}-05$ & $6,74 \mathrm{E}-05$ & $4,40 \mathrm{E}-05$ & $8,66 \mathrm{E}-05$ \\
$\mathrm{Ni}^{2+}$ (ion) & $\mathrm{kg}$ & $4,96 \mathrm{E}-06$ & $2,89 \mathrm{E}-05$ & $1,61 \mathrm{E}-06$ & $4,55 \mathrm{E}-06$ \\
\hline & & & &
\end{tabular}

Estes resultados foram tratados com o propósito de refletir o desempenho ambiental dos sistemas de aquecimento de água, no exercício da função estabelecida para o estudo.

\section{RESULTADOS E DISCUSSÃO}

Tomando-se os dados da Análise de Inventário procedeu-se a Avaliação de Impactos de Ciclo de Vida (AICV) dos quatro arranjos analisados por meio da aplicação do método ReCiPe Midpoint $(\mathrm{H})$. Os resultados desta ação aparecem descritos na Tabela 3.

A comparação dos perfis de impacto revela que o aquecimento de água efetuado por resistência elétrica tem desempenho ambiental superior ao demonstrado pelos homólogos em três de seis categorias avaliadas pelo estudo sempre se resguardando as condições em que a ACV foi conduzida.

Tal supremacia foi dividida com o sistema híbrido nos casos de Mudanças Climáticas (CC), e das depleções Hídrica (WD) e de Recursos Fósseis (FD). O sistema a gás expressou os piores desempenhos dentre as opções analisadas nos seis efeitos avaliados, sendo que em termos de WD, o arranjo foi seguido pelo aquecimento solar. Quanto às "Mudanças Climáticas" (CC) constata-se um fenômeno interessante, mas previsível. Para todos os sistemas analisados as contribuições mais significantes vinculam-se a produção de energia elétrica e térmica. No sistema a gás devem se destacar emissões de dióxido de carbono $\left(\mathrm{CO}_{2}\right)$ de $13,2 \mathrm{kgCO}_{2}$ eq./FR, ou $98,4 \%$ do total decorrentes de queima do gás natural no aquecimento da água de banho. Destaque-se ainda que perdas de $\mathrm{CO}_{2}$ e de metano $\left(\mathrm{CH}_{4}\right)$ associadas à 
produção, ao transporte, e a vazamentos de gás natural montam 1,6\% do total de contribuição do modal.

Tabela 3. Comparação de desempenho ambiental entre sistemas de aquecimento de água.

\begin{tabular}{lccccc}
\hline Categoria de Impacto & Unidade & Elétrico & Solar & Gás & Híbrido \\
\hline Mudanças Climáticas (CC) & $\mathrm{kg} \mathrm{CO}_{2}$ eq & $7,09 \mathrm{E}-02$ & $9,80 \mathrm{E}-02$ & $1,35 \mathrm{E}+01$ & $7,83 \mathrm{E}-01$ \\
Acidificação Terrestre (AC) & $\mathrm{kg} \mathrm{SO}_{2}$ eq & $2,69 \mathrm{E}-04$ & $4,36 \mathrm{E}-04$ & $1,64 \mathrm{E}-03$ & $3,64 \mathrm{E}-04$ \\
Eutrofização aquática (EUA) & $\mathrm{kg} \mathrm{P}_{\text {eq }}$ & $3,14 \mathrm{E}-05$ & $6,95 \mathrm{E}-05$ & $8,90 \mathrm{E}-05$ & $6,23 \mathrm{E}-05$ \\
Depleção de Recursos Hídricos (WD) & $\mathrm{m}^{3}$ & $5,84 \mathrm{E}-02$ & $1,17 \mathrm{E}-01$ & $1,21 \mathrm{E}-01$ & $5,78 \mathrm{E}-02$ \\
Depleção de Metais (MD) & $\mathrm{kg} \mathrm{Fe}_{\text {eq }}$ & $1,62 \mathrm{E}-02$ & $4,40 \mathrm{E}-02$ & $2,87 \mathrm{E}-01$ & $4,04 \mathrm{E}-02$ \\
Depleção de Recursos Fósseis (FD) & $\mathrm{kg} \mathrm{óleo} \mathrm{eq}$ & $2,25 \mathrm{E}-02$ & $3,24 \mathrm{E}-02$ & $1,37 \mathrm{E}-01$ & $2,63 \mathrm{E}-02$ \\
\hline
\end{tabular}

Para o modal elétrico as contribuições quanto a $\mathrm{CC}\left(0,07 \mathrm{kgCO}_{2 \mathrm{eq}} / \mathrm{FR}\right)$ remetem a emissões de $\mathrm{CO}_{2}$ e $\mathrm{CH}_{4}$ de origem fóssil, respectivamente $89,3 \%$ e 2,6\% do total. As perdas de $\mathrm{CO}_{2}$ estão diversificadas, com destaque para a queima de gás natural na geração de energia elétrica equivalente a $52,6 \%$ do total, modal cuja contribuição para a oferta interna de eletricidade do Brasil em 2011 foi de 4,4\% (Brasil, 2012a). Ressaltam-se também os combustíveis, que em suas intervenções como gás natural e óleo combustível para geração de energia térmica, e diesel para transporte, somam $15 \%$.

As emissões de $\mathrm{CH}_{4}$ provem da purificação de gás natural em unidades produtoras no Brasil e na Bolívia, e vazamentos nas tubulações de transporte. A esta ação se atribui ainda parte dos lançamentos de $\mathrm{CO}_{2}$ do sistema elétrico, em virtude do transporte do gás natural, e da queima de excedentes em flair. Dados divulgados pela Agência Nacional de Petróleo, Gás Natural e Biocombustíveis (ANP) informam que vazamentos e queima de gás natural ocorridos em 2012 no estado do Rio de Janeiro, maior produtor nacional $\left(10,3 \mathrm{MMm}^{3}\right)$, responderam por 3,3\% da extração no período. O Estado de São Paulo, outro produtor inscrito na cobertura geográfica do estudo $\left(2,0 \mathrm{MMm}^{3}\right)$ seguiu a mesma tendência. A ANP reporta que a taxa nacional de perda de gás natural em 2012 atingiu $1,44 \mathrm{MMm}^{3}$, ou seja, 5,6\% do total processado no país (ANP, 2013).

Ainda quanto ao sistema de aquecimento elétrico devem ser destacadas emissões de $\mathrm{CO}_{2}$ e $\mathrm{CH}_{4}$ de ocupação do solo para conformação de reservatórios de usinas hidrelétricas. Essas gerações decorrem da decomposição microbiológica em condição aeróbia e anaeróbia, de cobertura vegetal. Ainda que o aporte monte 3,4\% de contribuição do sistema elétrico para CC os resultados obtidos por este estudo a partir do consumo de energia elétrica (Tabela 1), e de emissões de $\mathrm{CO}_{2}$ e $\mathrm{CH}_{4}$ por uso do solo (Tabela 2) de 1,26 g/kWh e 0,17 g/kWh corroboram as estimativas de Silva et al. (2013) para as emissões dos mesmos gases na operação regular da Usina de Itaipu: 1,08 g/kWh e 0,13 g/kWh.

$\mathrm{O}$ aquecimento solar tem $89,5 \%$ dos impactos para $\mathrm{CC}$ associados a emissões de $\mathrm{CO}_{2}$. As fontes geradoras dessa emissão mostraram-se tão variadas quanto as do sistema elétrico. Nesse caso, os aportes desde a queima de gás natural para geração de eletricidade perfazem $39,8 \%$ do total.

Já os lançamentos para o ar de $\mathrm{CH}_{4}$ fóssil, e $\mathrm{CH}_{4}$ de ocupação do solo, respectivamente $3,4 \%$ e 2,5\%, são de procedências congêneres com as descritas para o sistema elétrico. Esses ônus se justificam pela influência da energia elétrica de $0,60 \mathrm{kWh} / \mathrm{p}$, sobre o aquecimento solar para que este atenda a função definida para o estudo. Neste caso a taxa de emissões de $\mathrm{CH}_{4}$ de uso do solo é de $0,19 \mathrm{~g} / \mathrm{kWh}$. O desempenho ambiental do sistema híbrido segue o 
mesmo diapasão de seus predecessores com $89,6 \%$ de contribuição por $\mathrm{CO}_{2}$ fóssil, além de $3,7 \%$ e $2,3 \%$ de $\mathrm{CH}_{4}$ de procedência fóssil e de uso do solo $(0,17 \mathrm{~g} / \mathrm{kWh})$. A influência da energia elétrica também é marcante aqui por conta do aporte de $0,45 \mathrm{kWh} / \mathrm{p}$.

Quanto à Acidificação Terrestre (AC) o desempenho expresso pelo sistema a gás de $1,64 \mathrm{gSO}_{2 \text { eq. }} / \mathrm{FR}$ baseia-se em emissões de óxidos de enxofre e nitrogênio $\left(\mathrm{SO}_{\mathrm{x}}\right.$ e $\left.\mathrm{NO}_{\mathrm{x}}\right)$ cujas contribuições valem $52,2 \%$ e $46,3 \%$. No grupo dos sulfurados sobressaem-se perdas de dióxido de enxofre $\left(\mathrm{SO}_{2}\right)$ com participação global de $26,6 \%$ procedentes de combustão de carvão mineral (20,3\%) que em 2010 suportou 79\% do grid energético da China (IEA, 2011), dado que a Usina Hidrelétrica de Três Gargantas operava apenas em regime parcial; e, do uso de diesel em deslocamentos transoceânicos $(17,6 \%)$ para traslado deste sistema até o Brasil. As emissões de $\mathrm{NO}_{x}$ provêm de processos de combustão completa e incompleta para geração de vapor em atividades industriais $(7,2 \%)$; transportes rodoviários e transoceânicos $(5,8 \%)$ e, no caso do dióxido de nitrogênio $\left(\mathrm{NO}_{2}\right)$, do aquecimento da água de banho $(4,4 \%)$. Foi, porém na produção de resina epóxi que figuraram as principais emissões de $\mathrm{NO}_{\mathrm{x}}$ com $62,9 \%$ do total para AC. Essa influência no desempenho do sistema a gás será discutida prontamente.

As contribuições dos sistemas de aquecimento elétrico, solar e híbrido para AC são discretas, expressas quanto a magnitude em décimos de milésimos. Uma análise detalhada da questão indicou haver correspondência entre emissões gasosas que contribuem para esta categoria de impacto e os consumos elétricos associados a cada sistema. Notou-se afinidade entre perfis de desempenho dos três sistemas, quanto às emissões de $\mathrm{SO}_{2}: 61,7 \%$ no sistema elétrico; 66,3\% para o solar; e 67,4\% no híbrido; de $\mathrm{NO}_{\mathrm{x}}$ : $26 \%$; $24,3 \%$; e 23,8\% e; de amônia $\left(\mathrm{NH}_{3}\right): 11,5 \%$; 8,9\%; e 8,3\%. Em todos os casos, o $\mathrm{SO}_{2}$ advém do enxofre presente no óleo combustível, cujo teor máximo permitido é $2,5 \%$ ww usado para geração elétrica no Brasil (Petrobras, 2013). Observe-se que a participação dos derivados de petróleo na oferta interna de energia elétrica por fonte em 2011 correspondeu a 2,6\% (Brasil, 2012a).

Emissões de $\mathrm{NO}_{\mathrm{x}}$ dos sistemas em análise vinculam-se outra vez à oferta interna de energia elétrica brasileira; além do óleo combustível figura nesse contexto a queima de biomassa, modal em franca expansão no país, cuja participação na oferta interna de eletricidade de 2011 remeteu a 6,6\% (Brasil, 2012a). As perdas atmosféricas de $\mathrm{NO}_{x}$ procedem igualmente de ações de transporte. Emissões de $\mathrm{NH}_{3}$ figuram nesta análise a partir de queima de biomassa, em virtude do uso de fertilizantes nitrogenados nesses cultivos. Em 2011, os derivados de cana responderam por $62,1 \%$ da biomassa usada para eletricidade (Brasil, 2012a). As exigências nutricionais de $\mathrm{N}$ para tal cultivo variam em função de diversos fatores; Rossato et al. (2005) apontam que para produtividades agrícolas entre 80-100 t ha ${ }^{-1}$ ou superiores a $100 \mathrm{t} \mathrm{ha}^{-1}$, a adubação nitrogenada deve ser, respectivamente de $100 \mathrm{e}$ $120 \mathrm{~kg} \mathrm{ha}^{1}$ para cana-planta, e $30 \mathrm{~kg} \mathrm{ha}^{-1}+30-60 \mathrm{~kg} \mathrm{ha}^{-1}$ em cobertura para cana-soca. Os autores argumentam que, muito embora as perdas de $\mathrm{N}$ para o ar, água, e solo que derivam de intempéries e de atividades agrícolas sejam variáveis, estas tendem a ser mais intensas sob a forma de $\mathrm{NH}_{3}$ no caso do Brasil, dada a predominância de caráter ácido em seus lato solos cultiváveis.

Perdas hídricas de fosfatos $\left(\mathrm{PO}_{4}{ }^{3-}\right)$ foram absolutas em impacto registrados em termos de Eutrofização aquática (EUA), refletindo $97,5 \%$ do total estimado para o sistema a gás, e superando os $99 \%$ para as demais alternativas analisadas. Nesse quadro, ganha evidência o uso de adubos fosfatados na produção de biomassa para eletricidade. Rossato et al. (2005) comentam que a produtividade de cana-de-açúcar é mais sensível a $\mathrm{N}$ e $\mathrm{K}$, do que a P. Porém, os autores advertem que na ausência de fósforo seus homólogos fertilizantes são pouco efetivos; assim, sugerem que em desempenhos agrícolas superiores a $100 \mathrm{t} \mathrm{ha}^{-1}$ se dosem $30 \mathrm{kgP}_{2} \mathrm{O}_{5} \mathrm{ha}^{-1}$. Demattê (2004) constatou que a taxa de fixação de $\mathrm{P}$ ao solo no cultivo de cana é da ordem de $30 \%$ do total aplicado; destes, até $45 \%$ podem ser deslocados para 
coleções hídricas superficiais ou subterrâneas por intempéries, ou de atividades relacionadas ao próprio cultivo.

Os impactos sob a forma de "Depleção de Recursos Hídricos" (WD) concentram-se em mais de $99 \%$, no consumo de água para preparação do banho. Os valores de demanda hídrica por modal de aquecimento que constam da Tabela 1 justificam as supremacias dos sistemas elétrico e híbrido sobre as demais variantes. Desde os dados indicados no relatório de CIRRA nota-se que as razões de consumo de água entre os sistemas a gás e solar e o modal elétrico são $\mathrm{R}_{1}=2,08$ e $\mathrm{R}_{1}{ }_{1}=2,00$; e com o sistema híbrido, de $\mathrm{R}_{2}=2,11$ e $\mathrm{R}_{2}=2,03$. Esses índices apontam que para disponibilizar água a $45^{\circ} \mathrm{C}$ por 8,1 minutos nas condições em análise, os sistemas a gás e solar têm consumos hídricos superam em mais de $100 \%$ os dispêndios feitos pelas opções elétrica e híbrida. Além disso, uma apreciação dos valores da Tabela 1 mostra que para todos os sistemas em análise, os aquecimento e uso da água no banho totalizam algo mais que 57\% do valor de WD aportado na Tabela 2. O restante desse desempenho se deve a perdas hídricas na atividade de distribuição que nas estatísticas da Associação Brasileira de Engenharia Sanitária (ABES) de 2011 alcançam 40\% no caso do município de São Paulo (ABES, 2013), e tratamento, da ordem de 3,0\%.

O desempenho quanto à "Depleção de Metais" (MD) de todos os modais de aquecimento se apoia em dois aspectos: tipo e quantidade de material metálico empregado na conformação da unidade. Assim, ainda que com uma taxa de utilização de apenas 1,37E-04p (Tabela 1), o sistema a gás teve aproveitamento inferior aos dos homólogos, por ser composto de: $3,45 \mathrm{~kg}$ aço $\mathrm{C} ; 1,58 \mathrm{~kg}$ cobre (recoberto de estanho); 0,59 $\mathrm{kg}$ latão; 0,47 $\mathrm{kg}$ de aço Inox; e 0,24 kg alumínio. Neste caso os consumos de: Ferro (24,4\%); Manganês (34,6\%), metal cuja presença no aço C chega a 2,0\% para a aplicação pretendida (ArcelorMittal, 2012); e Cromo $(16,2 \%)$ que no aço $\mathrm{C}$ aporta até $0,40 \%$, mas que no aço inox varia entre $16-30 \%$ no uso em questão (Gerdau, 2003) montam as contribuições mais expressivas. No outro extremo figura o sistema elétrico. Sua taxa de utilização de 5,48E-04p é a mais elevada entre as opções estudadas, mas há pequena quantidade de componentes metálicos: 56,3 g cobre, ou seja, $77,3 \%$ do impacto do sistema nesta categoria; e 9,40 g arames de ligas metálicas FeCrAl que corresponde a 10,9\%. O aquecimento solar ocupou neste caso uma posição intermediária. Foram decisivos aqui os consumos de aço Inox $(7,58 \mathrm{~kg})$, alumínio $(5,86 \mathrm{~kg})$, e cobre $(2,16 \mathrm{~kg})$ cujos aportes remetem a 16,3\%, 0,08\%, e 62,6\% do total de MD. Como o sistema híbrido foi modelado como a somatória das opções elétrica e solar esses precursores agiram sobre seu desempenho. Assim, provêm impactos para MD nesse modal, os consumos de cobre $(61,7 \%)$, cromo $(9,8 \%)$, e ferro $(6,81 \%)$ e manganês $(4,23 \%)$.

Em termos de "Depleção de Recursos Fósseis" (FD) os sistemas mostraram correlação com Mudanças Climáticas quanto às ações contribuintes. O destaque negativo voltou a ser o sistema a gás cujo desempenho alcançou 0,14 kgóleo $_{\mathrm{eq}} / \mathrm{FR}$. O resultado deveu-se em 44,5\% ao consumo de gás natural, ao que se seguem depleções de petróleo e carvão mineral de $29,6 \%$ e $19,6 \%$. Exatos 70,6\% da extração de gás, e 62,8\% da de petróleo destinaram-se à produção de resina epóxi para confecção da estrutura do sistema a gás, que ocorre a partir da reação de bisfenol A com epicloridrina em meio alcalino (Boustead, 1999). Do gás natural gera-se propeno $\left(\mathrm{C}_{3} \mathrm{H}_{6}\right)$, insumo essencial para formar epicloridrina. A síntese do bisfenol $\mathrm{A}$ se dá via cumeno, um derivado de $\mathrm{C}_{3} \mathrm{H}_{6}$ e de benzeno $\left(\mathrm{C}_{6} \mathrm{H}_{6}\right)$. As fontes usuais de $\mathrm{C}_{6} \mathrm{H}_{6}$ para produção de resina epóxi são exatamente gás natural e petróleo. Consumos restantes desses recursos destinam-se a geração de vapor de processo, dado que a produção de resina epóxi despende 140 MJ/kg produto (Boustead, 1999; Kočí e Loubal, 2012).

O desempenho do sistema a gás se completa com o aporte de carvão mineral: 19,6\% usado integralmente na produção de ferro gusa, intermediário da produção de aço C. O carvão mineral é usado nessa transformação como fonte de matéria: coque, com consumo médio da $0,15 \mathrm{~kg} / \mathrm{kg}$ gusa, e de energia em torno de $29 \mathrm{MJ} / \mathrm{kg}$ gusa (Energetics, Incorporated 
e United States, 2000). Os sistemas elétrico, solar e híbrido seguem a mesma orientação, porém com consumo de gás natural mais elevados: $64,3 \%, 54,8 \%$ e $52,4 \%$ que se vinculam à produção de eletricidade. O mesmo ocorre com o carvão mineral: 17,2\%, 18,2\% e 18,4\% que com seus derivados participou com $1,4 \%$ da oferta interna de energia elétrica do Brasil em 2011 (Brasil, 2012a). O uso de petróleo cru divide-se entre provimento de eletricidade para o grid, e produção de diesel para transporte.

\section{CONCLUSÕES}

A comparação dos quatro sistemas de aquecimento de água mostrou que, para as condições e premissas em que foi realizado o estudo, os modais elétrico e híbrido apresentam desempenho ambiental superior às das unidades solar e a gás. Essa dedução baseia-se em dois fatores. O primeiro deles consiste do fato de os consumos elétricos medidos pelo CIRRA serem próximos entre si. Ou seja, ao longo dos doze meses de ensaios os sistemas híbrido e de aquecimento solar mostraram-se dependentes de suplementação elétrica mais além do que se poderia supor. O segundo fator é um desdobramento deste quadro, uma vez que todas as categorias de impacto analisadas foram influenciadas pelo elenco de fontes que suporta a oferta de eletricidade para o país. Outro efeito determinante do quadro que instalou referiu-se a manufatura do sistema a gás ocorrer na China, país em que a matriz energética se sustenta ainda em combustíveis fósseis. Uma ação proativa nesse campo compreende, portanto, a internalização deste processamento.

O estudo foi realizado para condições específicas em termos de modelagem do uso dos sistemas e assim, essas discussões devem avançar. Porém, recomenda-se que a leitura dada pela ACV siga sendo considerada dada a efetividade dos diagnósticos que proporciona.

\section{AGRADECIMENTOS}

Este trabalho foi desenvolvido com suporte financeiro da ASSOCIAÇÃO BRASILEIRA DA INDÚSTRIA ELÉTRICA E ELETRÔNICA - ABINEE.

\section{REFERÊNCIAS}

ASSOCIAÇÃO BRASILEIRA DE ENGENHARIA SANITÁRIA - ABES. Perdas em sistemas de abastecimento de água: diagnóstico, potencial de ganhos com sua redução e propostas de medidas para o efetivo combate. Relatório Técnico. São Paulo, 2013. 45p.

ASSOCIAÇÃO BRASILEIRA DE NORMAS TÉCNICAS - ABNT. NBR ISO 14040: gestão ambiental - avaliação do ciclo de vida - princípios e estrutura. Rio de Janeiro, 2009a. $21 \mathrm{p}$.

ASSOCIAÇÃO BRASILEIRA DE NORMAS TÉCNICAS - ABNT. NBR ISO 14044: gestão ambiental - avaliação do ciclo de vida - requisitos e orientações. 2009b. Rio de Janeiro, 2009b. 46p.

AGÊNCIA NACIONAL DE PETRÓLEO, GÁS E BIOCOMBUSTÍVEIS (Brasil). Anuário estatístico brasileiro do petróleo, gás natural e biocombustíveis. 2013. BrasíliaDF, 2013. 76p.

ARCELORMITTAL BRASIL. Guia do aço - aços longos. Belo Horizonte, 2012. 132p. Disponível em: http://www.arcelor.com.br. Acesso em: 29 jan. 2014. 
BOUSTEAD, I. Eco-profiles for the european plastic industry: liquid epoxy resins, 12. The Brussels: APME, 1999. Disponível em: http://lca.apme.org. Acesso em: 16 jan. 2014.

BRASIL. Ministério de Minas e Energia. Balanço energético nacional - 2011. Brasília-DF, 2012. 282p.

BRASIL. Ministério de Minas e Energia. Empresa de Pesquisas Energéticas - EPE. Avaliação da eficiência energética para os próximos 10 anos (2012-2021). Nota Técnica DEA 16/12. Rio de Janeiro, 2012. p. 26. Disponível em: http://www.epe.gov.br. Acesso em: 5 jan. 2014.

BUYLE, M.; BRAET, J.; AUDENAERT, A. Life cycle assessment in the construction sector: a review. Renewable and Sustainable Energy Reviews, v. 26, p. 379-388, 2013. http://dx.doi.org/10.1016/j.rser.2013.05.001

CHOW, T. T.; JI, J. Environmental life-cycle analysis of hybrid solar photovoltaic/thermal systems for use in Hong Kong. International Journal of Photoenergy, v. 2012, 2012. http://dx.doi.org/10.1155/2012/101968

CENTRO INTERNACIONAL DE REFERÊNCIA EM REÚSO DE ÁGUA - CIRRA. Avaliação do consumo de insumos (água, energia elétrica e gás) em chuveiro elétrico, aquecedor a gás, chuveiro híbrido, aquecedor solar e boiler elétrico. Relatório Técnico. São Paulo, 2010. 64p.

CONFEDERAÇÃO NACIONAL DA INDÚSTRIA - CNI. Pesquisa CNI-IBOPE: retrato da sociedade brasileira: hábitos de consumo e endividamento. Brasília-DF, 2012. 37p. Disponível em: http://www.ibope.com.br. Acesso em: 13 fev. 2014.

DEMATTÊ, J. Recuperação e manutenção da fertilidade dos solos. Visão Agrícola, v. 1, 2004. p. 48-59.

ENERGETICS, INCORPORATED; UNITED STATES. Department of Energy. Energy and environmental profile of the US Iron \& Steel Industry. 2000. Disponível em: http://www.oit.doe.gov. Acesso em: 27 dez. 2013.

ERDAU S.A. Aços Finos Piratini. Manual de aços. Charqueada, 2003. 106p. Disponível em: ftp://ftp.demec.ufpr.br. Acesso em: 30 jan. 2014.

GOEDKOOP, M.; HEIJUNGS, R.; HUIJBREGTS, M.; SCHRYVER, A.; STRUIJS, J.; VAN ZELM, R. ReCiPe: a life cycle impact Assessment method which comprises harmonized category indicators at the Midpoint and the Endpoint Level. Report I: Characterization. 2009. Disponível em: http://www.lciarecipe.net. Acesso em: 13 fev. 2014.

HANSEN, A. P. Análise do efeito em termos de desempenho ambiental da substituição de eteno de origem fóssil por equivalente renovável na produção de poliestireno 2013. 269p. Dissertação (Mestrado em Engenharia Química) - Escola Politécnica, Universidade de São Paulo, São Paulo, 2013.

HAZAMI, M.; NAILI, N.; ATTAR, I.; FARHAT, A. Solar water heating systems feasibility for domestic requests in Tunisia: thermal potential and economic analysis. Energy Conversion Management, v. 76, p. 599-608, 2013.

http://dx.doi.org/10.1016/j.enconman.2013.07.079 
INSTITUTO BRASILEIRO DE GEOGRAFIA E ESTATÍSTICA - IBGE. PNAD - pesquisa nacional por amostra de domicílio 2001-2011. 2012. Disponível em: http://seriesestatisticas.ibge.gov.br/. Acesso em: 5 jan. 2014.

INTERNATIONAL ENERGY AGENCY - IEA. Energy Balance of Non-OECD countries. Section II. 49. Paris, 2011.

KATTAN, P.; RUBLE, I. An economic assessment of four different boilers for residential heating in Lebanon. Energy and Buildings, v. 50, p. 282-289, 2012. http://dx.doi.org/10.1016/j.enbuild.2012.02.057

KOČÍ, V.; LOUBAL, T. LCA of liquid epoxy resin produced based on propylene and on glycerin. Acta Environmentalica Universitatis Comenianae, v. 20, n. 1, p. 62-67, 2012 .

KORONEOS, C. J.; NANAKI, E. A. Life cycle environmental impact assessment of a solar water heater. Journal of Cleaner Production, v. 37, p. 154-161, 2012. http://dx.doi.org/10.1016/j.jclepro.2012.07.001

LORENZETTI. Aquecedor de água a gás tipo instantâneo, Modelo L-8. São Paulo, 2011a. $19 \mathrm{p}$.

LORENZETTI. Maxi ducha: manual de instruções de instalação e garantia. São Paulo, 2011b. 3p.

PETROBRAS. Escola de Ciências e Tecnologias de Abastecimento. Óleo combustível: informações técnicas. 2013. Disponível em: http://www.petrobras.com.br. Acesso em: 04 fev. 2014.

ROSSATTO, R.; DIAS, F. L. F.; INTERNATIONAL PLANT NUTRITION INSTITUTE INPI. Encarte de Informações Agronômicas, n. 110, p. 6-11, jun. 2005.

SÃO PAULO (Estado). Secretaria de Energia. Anuário estatístico de energéticos por município no estado de São Paulo. São Paulo, 2012. 126p. Disponível em: http://www.energia.sp.gov.br. Acesso em: 5 jan. 2014.

SILVA, G. A.; RIBEIRO, F. M.; KULAY, L. Hydropower life-cycle inventories: methodological considerations and results based on a Brazilian experience. In: Life cycle assessment of renewable sources, p. 241-267, 2013. http://dx.doi.org/10.1007/978-1-4471-5364-1_11

SUMPER, A.; ROBLEDO-GARCIA, M.; VILLAFAFILA-ROBLES, R.; BERGAS-JANE, J. ANDRES-PEIRO, J. Life-cycle assessment of a photovoltaic system in Catalonia (Spain). Renewable and Sustainable Energy Reviews, v. 15, n. 8, p. 3888-3896, 2011. http://dx.doi.org/10.1016/j.rser.2011.07.023

SUGAWARA, E. T. Comparação dos desempenhos ambientais do B5 etílico de soja e do óleo diesel, por meio da Avaliação do Ciclo de Vida (ACV). 2012. 104p. Dissertação (Mestrado em Engenharia Química) - Escola Politécnica, Universidade de São Paulo, São Paulo, 2012. 